\title{
IoT in Agriculture Industry
}

\author{
Ekky Novriza Alam \\ Sekolah Teknik Elektro dan Informatika \\ Institut Teknologi Bandung \\ Bandung, Indonesia \\ ekkynovrizaalam@students.itb.ac.id
}

\begin{abstract}
Indonesia is known as an agricultural country that has an agricultural area of 7.1 million hectares in 2018. The agricultural sector is one sector that has great potential to get many benefits by implementing IoT technology. IoT implementation has several obstacles such as hardware, software, communication technology, and security. This paper aims to describe IoT-related studies in the agricultural sector that have been carried out since 2010 in the hope of providing evidence that transforming the traditional agricultural sector into a modern agricultural sector is very possible in Indonesia.
\end{abstract}

Keywords-IoT, Agriculture, Industry, IoT Application

\section{Pendahuluan}

Perkembangan teknologi sudah sangat pesat dan memberikan dampak pada banyak sektor, terutama sektor industri. IoT sebagai salah satu bukti perkembangan teknologi sampai saat ini mampu memberikan banyak perubahan pada berbagai hal di industri. Sebagai contoh perubahan yang terdapat pada sektor transportasi dengan berbagai aplikasi tracking sebagai bentuk end-user system dan berbagai alat-alat yang bekerja otomatis dengan memanfaatkan IoT pada sektor manufaktur[1].

IoT terbukti banyak meningkatkan efektifitas dan efisiensi baik ditingkat operasional bahkan tingkat strategis. Contohnya sistem monitoring intelegen untuk memonitor temperature didalam refrigator trucks menggunakan sensor dan teknologi jaringan wireless[2]. Sistem pendeteksi api otomatis yang dapat membawa pengelolaan sistem pemadam kebakaran di China dapat meningkat ke level yang lebih tinggi[3].

Beberapa sektor industri telah terlihat memiliki peningkatan ketertarikan dengan teknologi IoT[4]. Sektor pertanian, industri pengolahan makanan, pemantauan lingkungan, pengawasan keamanan, dan lainnya sudah terlihat memiliki beberapa proyek IoT yang telah berjalan.

\section{LATAR BELAKANG}

Sektor pertanian merupakan salah satu sektor yang memiliki potensi besar mendapatkan manfaat yang banyak dengan penerapan teknologi IoT. Efektifitas dan efisiensi dari lahan, bibit, air dan pupuk sebagai bahan baku, sampai melakukan monitoring secara real-time selama 7x24 jam sangat mungkin diterapkan dengan IoT.

The Food and Agricultural Organization of the United Nation (FAO) memprediksi bahwa pada tahun 2050 kebutuhan pangan akan meningkat sebanyak $70 \%$ karena populasi manusia akan mencapai 9,6 Milyar[5]. Indonesia dikenal sebagai negara agraris yang memiliki luas wilayah pertanian sebesar 7,1 juta hektar pada tahun 2018[6]. Walaupun jumlah itu mengalami penurunan dari tahun sebelumnya yang berjumlah 7,75 juta hektar.

Dengan wilayah pertanian yang seluas itu, terlihat produksi jumlah hasil pertanian yang dapat dihasilkan belum mendapatkan hasil yang optimal. Terlihat pada Tabel 1 Dinamika 
Produksi Tanaman Pertanian, 2000-2013, jumlah produksi padi di Indonesia belum mengalami hasil yang stabil,bahkan cenderung mengalami penurunan kecuali direntang tahun 2005-2009[7].

TABel 1 Dinamika Produksi Tanaman Pertanian, 2000-2013

\begin{tabular}{|c|c|c|c|}
\hline \multirow{2}{*}{ Tahun } & \multicolumn{3}{|c|}{ Pertumbuhan (\%/tahun) } \\
\cline { 2 - 4 } & Padi Sawah & $\begin{array}{c}\text { Padi } \\
\text { Ladang }\end{array}$ & $\begin{array}{c}\text { Total } \\
\text { Padi }\end{array}$ \\
\hline $\begin{array}{c}2000- \\
2004\end{array}$ & $1,00^{\text {a }}$ & 1,68 & 1,03 \\
\hline $\begin{array}{c}2005- \\
2009\end{array}$ & 3,56 & 2,29 & 3,49 \\
\hline $\begin{array}{c}2010- \\
2013\end{array}$ & 1,68 & 4,31 & 1,82 \\
\hline $\begin{array}{c}\mathbf{2 0 0 0 -} \\
\mathbf{2 0 1 3}\end{array}$ & $\mathbf{2 , 1 9}$ & $\mathbf{2 , 7 2}$ & $\mathbf{2 , 2 2}$ \\
\hline
\end{tabular}

Beberapa negara lain sudah mencoba untuk meningkatkan produksi sektor pertanian mereka dengan mulai menerapkan teknologi IoT seperti India, Australia dan Amerika[8]. Hal ini menjadi peluang untuk Indonesia sebagai negara agraris untuk meningkatkan produksi sektor pertanian dengan teknologi IoT. Penelitian-penelitian yang membahas tentang IoT sudah mengalami peningkatan yang pesat[8]. Terlihat pada Gambar 1 Peningkatan penelitian terkait "IoT in Agriculture" di Scopus, peningkatan terjadi hampir disetiap tahun.

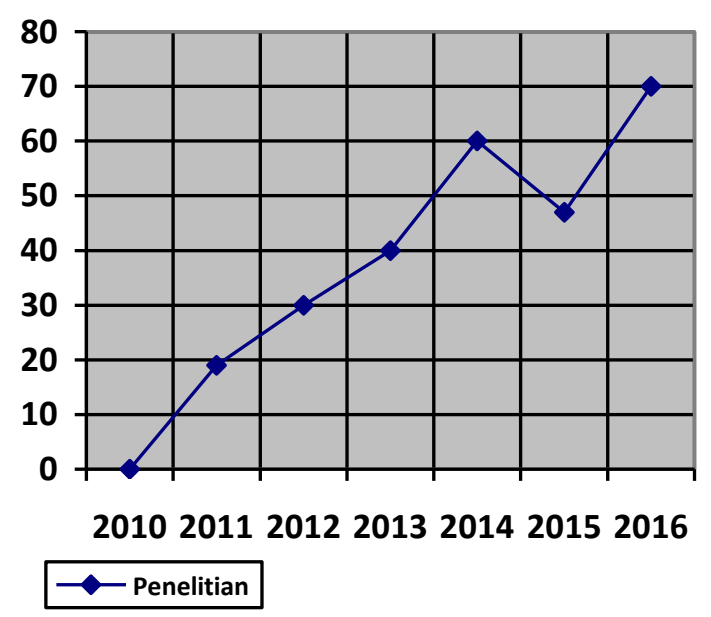

\section{Gambar 1 Peningkatan penelitian terkait "IoT in Agriculture" di Scopus}

Paper ini bertujuan untuk memaparkan penelitian-penelitian terkait IoT di sektor pertanian yang telah dilakukan sejak tahun 2010 dengan harapan dapat memberikan bukti bahwa mengubah sektor pertanian tradisional menjadi sektor pertanian modern sangat mungkin dilakukan di Indonesia. 


\section{INTERNET OF THINGS}

Struktur IoT dibangun berdasarkan 3 lapisan yaitu lapisan persepsi (sensing), lapisan jaringan (data transfer), dan lapisan aplikasi (data storage and manipulation)[9].

\section{A. Lapisan persepsi}

Sensor adalah hal utama pada lapisan ini. Teknologi yang digunakan pada lapisan ini adalah WSN, RFID, dan NFC. Wireless Sensor Node (WSN) terdiri dari modul pemrosesan, biasanya unit mikrokontroler daya rendah (MCU), satu atau lebih modul sensor yang dapat berupa analog atau perangkat penginderaan digital eksternal atau tertanam dan yang terakhir modul komunikasi RF, biasanya mendukung daya rendah teknologi komunikasi nirkabel.

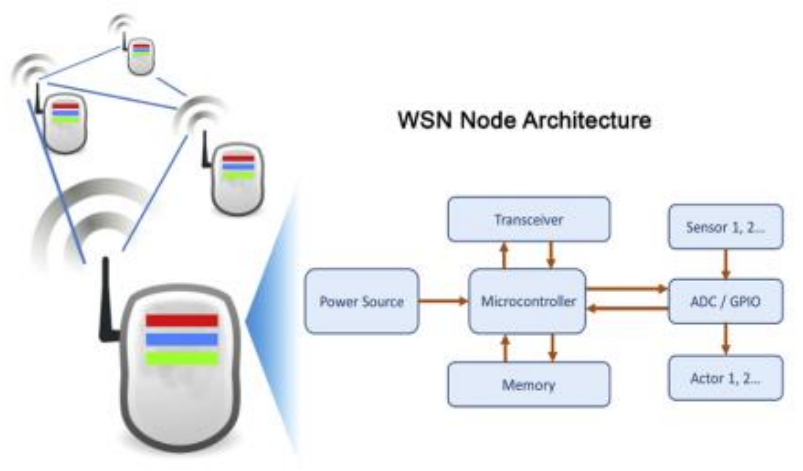

\section{Gambar 2 Arsitektur dari WSN}

Teknologi ini sangat cocok digunakan untuk sistem kontrol dan pengawasan pada proses produksi, penanaman ataupun penyimpanan. Beberapa penelitian terkait fasilitas penyimpanan dan logistic banyak yang berhubungan dengan WSN. Beberapa contoh penggunaan WSN terdapat pada Error! Reference source not found.

\section{B. Lapisan jaringan}

Teknologi jaringan berguna untuk melakukan komunikasi antar perangkat dan sistem diluar sistem IoT yang dibangun. Beberapa protocol komunikasi seperti 802.15.14, memfasilitasi jaringan perangkat dan menjembatani kesenjangan antara internet-enabled gateway dan node akhir. Pada Error! Reference source not found. terdapat beberapa teknologi komunikasi

\section{Lapisan aplikasi}

Lapisan ini adalah lapisan akhir yang merupakan wujud nyata yang mudah dilihat oleh user. Lapisan ini akan mengalami tantangan berupa sistem yang sangat heterogen. Seperti devices yang berbeda-beda, sistem operasi dan beberapa spesifikasi teknis lainnya. 


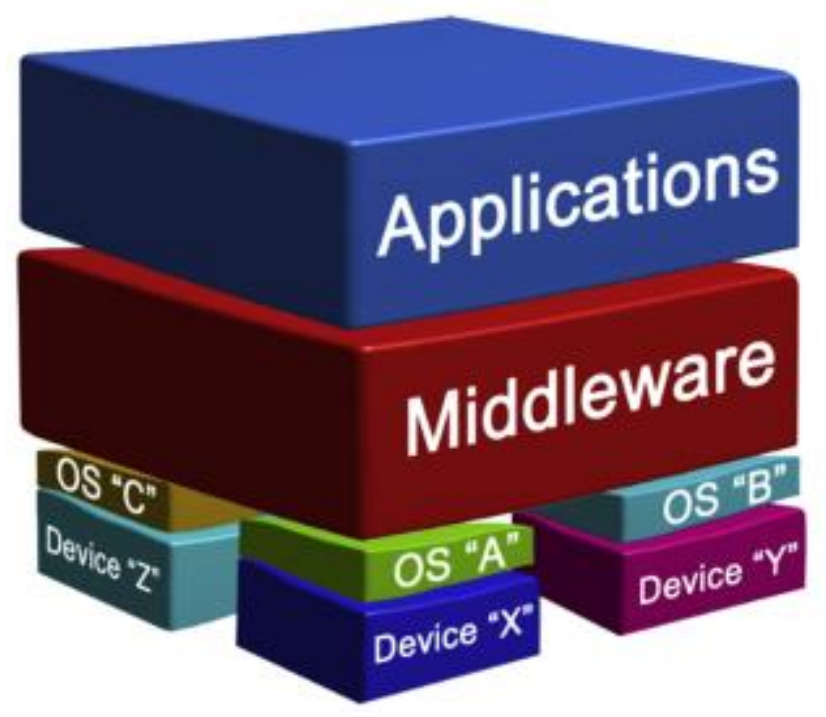

Gambar 3 Lapisan Aplikasi

\section{Pertanian dengan Iot}

Sektor pertanian dengan menggunakan IoT biasa disebut dengan istilah Precision Agriculture yang selanjutnya akan disingkat PA[10]. PA dianggap menjadi solusi untuk meningkatkan produksi jumlah produksi sektor pertanian dan dapat memberikan hasil yang stabil tiap masa produksinya. PA sendiri bertujuan untuk memberikan peningkatan dan optimasi proses-proses yang ada untuk memastikan produktivitas dapat mencapai jumlah terbaik. Hal tersebut dapat dicapai dengan adanya sistem yang dapat mengukur dengan cepat, handal dan dapat dibaca dengan mudah oleh petani sebagai gambaran tentang situasi yang sedang berterjadi diwilayah pertanian mereka.

PA juga memungkinkan adanya komunikasi yang saling terhubung antar mesin operasi otomatis untuk mengoptimalkan konsumsi energi, seperti penggunaan air dan listrik.

Hama yang selalu menjadi permasalahan bagi petani juga dapat diatasi dengan cepat dan tepat dengan sistem pengendali hama yang dapat siaga 7x24 jam[11]. Ketepatan sistem untuk membasmi hama juga dapat terus ditingkatkan seiring semakin lama sistem tersebut digunakan.

Pada tingkat understanding, informasi yang didapatkan dari berbagai alat dan sistem dikumpulkan dan diolah dengan algoritma tertentu untuk memberikan wawasan yang lebih baik tentang kejadian yang sedang terjadi[12]. Wawasan tersebut dapat digunakan untuk memahami situasi saat ini dan membuat prediksi berdasarkan inputan tersebut. Hasil prediksi selanjutnya dapat digunakan pada sistem peringatan dini tentang bahaya hama[11] dan sistem pengatur irigasi otomatis[13]. 
Aplikasi

Pada bab awal telah disampaikan bahwa penelitian dibidang IoT mengalami peningkatan. Penelitian terkait sensor IoT dan miniatur-miniatur perangkat IoT memberikan optimisme peralihan pertanian tradisional kepada pertanian modern Precision Agricultur(PA)[14].

\section{A. Sistem Irigasi Otomatis}

Irigasi menjadi hal yang penting bagi lahan pertanian yang memiliki jenis tanaman yang membutuhkan air yang cukup banyak. Tetapi air adalah sebuah sumberdaya yang terbatas untuk beberapa daerah. Oleh karena itu dibutuhkan sitem optimalisasi penggunaan air pada sistem irigasi. Sistem irigasi otomatis digunakan untuk mengukur dengan tepat kebutuhan air pada tanaman[15].

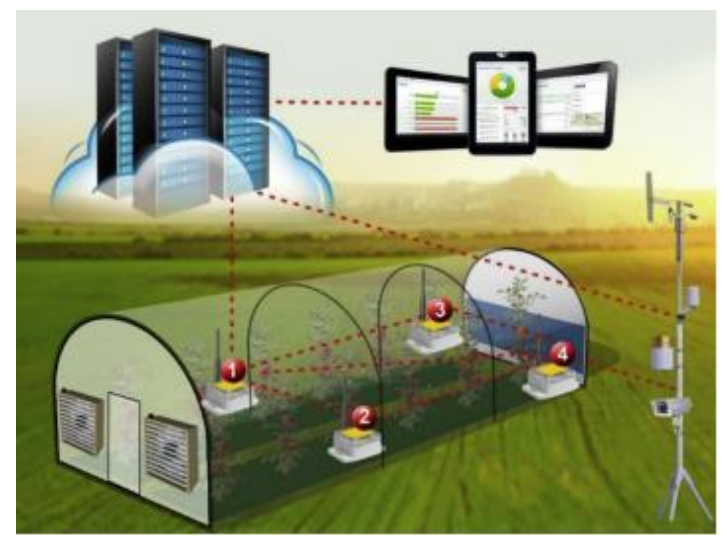

Gambar 4 Contoh solusi IoT untuk kebutuhan monitoring dan optimasi berdasarkan cloud analytics services

Kebutuhan air dapat diketahui melalui sensor-sensor yang terdapat pada tanah, tanaman dan lingkungan dengan mengukur beberapa variabel seperti suhu dan kelembapan. Kemudian informasi tersebut dikirim ke server analitik. Setelah itu server akan memberikan keputusan berdasarkan algoritma yang sudah ditentukan kepada alat pengatur irigasi. Disisi lain server juga menyediakan informasi berupa infografik yang dapat diakses oleh petani atau stakeholders lainnya.

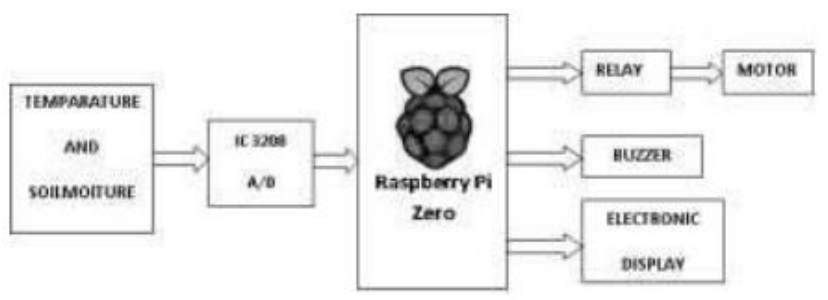

\section{Gambar 5 Diagram dari sistem IoT berbasis Raspberry Pi}

Penelitian lain mengusulkan sistem IoT berbasis Raspberry Pi yang membantu otomatisasi sistem irigasi. Sistem ini mengolah data yang dihasilkan sensor mengenai kelembapan dan suhu tanah, kelembapan udara, suhu udara dan durasi sinar matahari yang didapatkan per hari. Data ini kemudian diolah agar mendapatkan besaran air yang dibutuhkan untuk irigasi[13]. Gambaran detail mengenai alur kerja sistem ini tergambar pada Gambar 4 Contoh solusi IoT untuk kebutuhan monitoring dan optimasi berdasarkan cloud analytics services. Sistem ini mengolah informasi langsung tanpa mengirim informasi ke sistem cloud. 


\section{B. Sistem Kontrol dan Pengawasan}

Sistem kontrol dan pengawasan sangat bermanfaat di sektor pertanian, salah satunya untuk kontrol dan pengawasan gudang. Gudang sering menjadi sasaran hama perusak. Alat ini mampu memberikan pemberitahuan secara real-time kepada pengguna jika ada ancaman hama tikus[11].

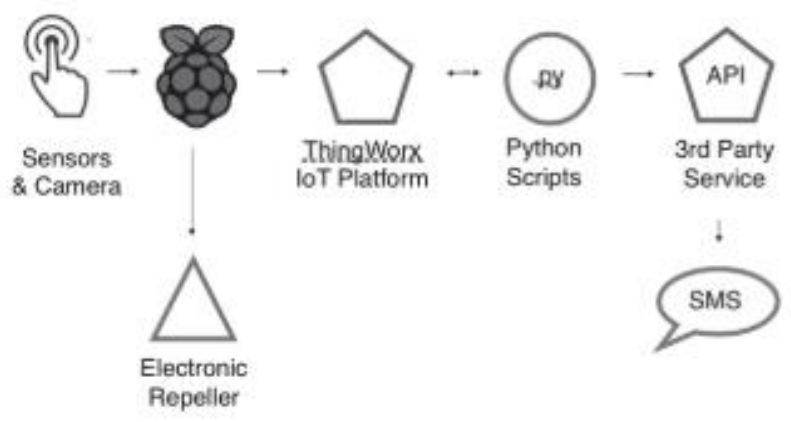

\section{Gambar 6 Arsitektur IoT pendeteksi hama tikus}

IoT digunakan untuk menghubungkan alat pendeteksi dan mengumpulkan informasi. Setelah dikumpulkan, dilakukan analisis data dengan menggunakan algoritma yang akan membantu untuk menentukan keakuratan dalam memberikan pemberitahuan kepada user dan mengaktifkan alat pembasmi tikus

\section{Sistem Pelacak Rantai Pasok Makanan}

RFID adalah teknologi yang banyak digunakan pada beberapa penelitian FSC (Food Supply Chain). Tag RFID digunakan sebagai alat untuk melacak produk-produk pertanian. Penelitian terbaru, mengikuti paradigma IoT, telah menggabungkan lebih dari satu sensor untuk memperkaya informasi status produk setiap kali ini direkam melalui RFID-nya[16].

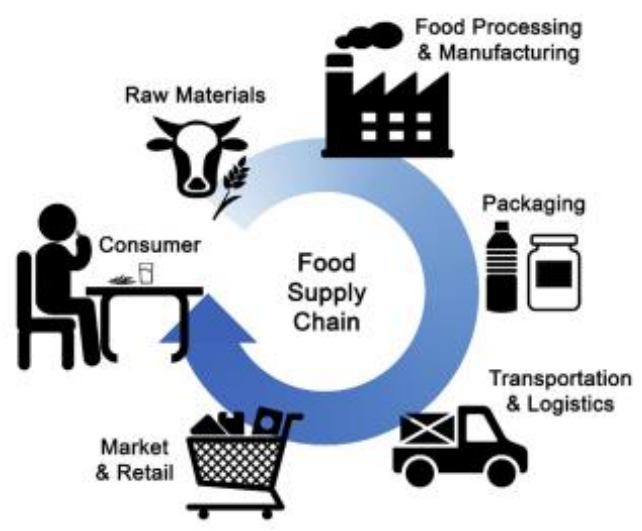

\section{Gambar 7 Skema Food Supply Chain}

\section{KESIMPULAN}

IoT diharapkan dapat mengoptimalkan produksi dari berbagai hal di sektor pertanian. Mulai dari lahan pertanian dan greenhouse dapat diberikan sistem pengawasan kondisi tumbuhan, kebutuhan air dan potensi gangguan hama. Oleh karenanya beberapa sumber daya seperti pupuk, air dan vitamin dapat digunakan secara efisien. Pengontrolan tahap produksi ini dapat memberikan keuntungan maksimal dan menimalkan biaya yang harus dikeluarkan. 
Namun disisi lain terdapat beberapa tantangan seperti keamanan dan kehandalan fasilitas jaringan yang menjadi hal penting pada IoT. Kemampuan untuk menyelaraskan semantic dari data yang disimpan menjadi sangat penting. Karena sumber yang sangat heterogen, sistem analitik harus mampu memberikan dukungan keputusan yang sesuai.

\section{REFERENSI}

[1] L. Da Xu, W. He, and S. Li, "Internet of things in industries: A survey," IEEE Trans. Ind. Informatics, vol. 10, no. 4, pp. 2233-2243, 2014.

[2] Y. Zhang, B. Chen, and X. Lu, "Intelligent Monitoring System on Refrigerator Trucks Based on the Internet of Things," in Wireless Communications and Applications, 2012, pp. 201-206.

[3] Y. Zhang and J. Yu, "A Study on the Fire IOT Development Strategy," Procedia Eng., vol. 52, pp. 314-319, 2013.

[4] Y. Li, M. Hou, H. Liu, and Y. Liu, "Towards a theoretical framework of strategic decision, supporting capability and information sharing under the context of Internet of Things," Inf. Technol. Manag., vol. 13, no. 4, pp. 205-216, Dec. 2012.

[5] FAO, "Global agriculture towards 2050," High Lev. Expert Forum-How to Feed world 2050, pp. 1-4, 2009.

[6] C. Indonesia, "BPS Sebut Luas Lahan Pertanian Kian Menurun," 2018. [Online]. Available: https://www.cnnindonesia.com/ekonomi/20181025153705-92-341433/bpssebut-luas-lahan-pertanian-kian-menurun. [Accessed: 07-Apr-2019].

[7] E. Ariningsih, "Dinamika produksi dan sumber dinamika produksi komoditas pertanian," pp. 63-92, 2012.

[8] A. Tzounis, N. Katsoulas, T. Bartzanas, and C. Kittas, "Internet of Things in agriculture, recent advances and future challenges," Biosyst. Eng., vol. 164, pp. 31-48, 2017.

[9] L. Atzori, A. Iera, and G. Morabito, "The Internet of Things: A survey," Comput. Networks, vol. 54, no. 15, pp. 2787-2805, 2010.

[10] N. Zhang, M. Wang, and N. Wang, "Precision agriculture-a worldwide overview," Comput. Electron. Agric., vol. 36, no. 2, pp. 113-132, 2002.

[11] T. Baranwal, Nitika, and P. K. Pateriya, "Development of IoT based smart security and monitoring devices for agriculture," Proc. 2016 6th Int. Conf. - Cloud Syst. Big Data Eng. Conflu. 2016, pp. 597-602, 2016.

[12] O. Körner and G. Van Straten, "Decision support for dynamic greenhouse climate control strategies," Comput. Electron. Agric., vol. 60, no. 1, pp. 18-30, 2008.

[13] R. Nageswara Rao and B. Sridhar, "IoT based smart crop-field monitoring and automation irrigation system," Proc. 2nd Int. Conf. Inven. Syst. Control. ICISC 2018, no. Icisc, pp. 478-483, 2018.

[14] A. Baggio, "Wireless sensor networks in precision agriculture," Netherlands IEEE Pervasive Comput., vol. 3, 2005.

[15] Y. Xijun, L. Limei, and X. Lizhong, "The Application of Wireless Sensor Network In the Irrigation Area Automatic System," Networks Secur. Wirel. Commun. Trust. Comput. Int. Conf., vol. 1, pp. 21-24, 2009.

[16] M. Maksimović, V. Vujovic, and E. Omanovic-Miklicanin, "A Low Cost Internet of Things Solution for Traceability and Monitoring Food Safety During Transportation," 2015. 